\title{
Reductions in dental decay in 3-year old children in Greater Glasgow and Clyde: repeated population inspection studies over four years
}

\author{
Alex D McMahon ${ }^{1 *}$, Yvonne Blair $^{2}$, David R McCall ${ }^{2}$ and Lorna MD Macpherson²
}

\begin{abstract}
Background: Dental decay remains one of the world's most prevalent diseases in childhood. It is unfortunate that the proportion of children suffering from oral disease is so high, given that dental decay is almost entirely preventable. The objective of this study was to examine dental inspection data from three-year old children to assess the extent to which the dental health in Greater Glasgow and Clyde had improved during the initial years of the Childsmile intervention programme.

Methods: Dental inspections of three-year old children in Greater Glasgow and Clyde were undertaken in the academic years of 2006/7 and 2007/8 (the baseline years), and again in 2008/9 and 2009/10 (after the intervention had begun). A standardised protocol suitable for the age group was used. The number of decayed, missing and filled teeth was calculated (ie $\mathrm{d}_{3} \mathrm{mft}$ ). If $\mathrm{d}_{3} \mathrm{mft}$ was $>0$ then a child was said to have 'obvious decay experience' into the dentine. Additional results examined the effect of socioeconomic status using the Scottish Index of Multiple Deprivation (SIMD).

Results: We inspected 10022 children (19\% of the population). The weighted percentage of children with decay experience was $26 \%$ in $2006 / 7,25 \%$ (2007/8), reducing to $18 \%$ (2007/8) and $17 \%(2009 / 10)$. When compared to the first baseline year of 2006/7, the OR was 0.91 for 2007/8 (0.79-1.06, $p=0.221), 0.63$ for 2008/9 $(0.55-0.72, p<0.001)$, and 0.50 for 2009/10 (0.43-0.58, $p<0.001)$. The weighted mean $d_{3}$ mft was 1.1 in 2006/7, 1.0 in 2007/8 $(p=0.869)$, 0.6 in 2008/9 ( $p<0.001)$ and 0.4 in 2009/10 ( $p<0.001$ ). Reductions in decay were seen in all socioeconomic groups.

Conclusions: This study demonstrates that it is possible to impact upon the prevalence and morbidity of dental decay across the socioeconomic spectrum in a population. The dental health of young children in the Greater Glasgow and Clyde area has improved in recent years.
\end{abstract}

\section{Background}

Dental decay remains one of the world's most prevalent diseases in childhood. The World Health Organisation estimates that dental decay affects between $60 \%$ and $90 \%$ of school age children and the vast majority of adults in developed countries [1]. Oral disease causes pain and much suffering for young children and often results in the necessity for general anaesthesia and surgical procedures. It is unfortunate that the proportion of children suffering from oral disease is so high, given that dental

\footnotetext{
* Correspondence: alex.mcmahon@glasgow.ac.uk

${ }^{1}$ Community Oral Health, Level 8, University of Glasgow Dental School, 378 Sauchiehall St, Glasgow, G2 3JZ, Scotland, UK

Full list of author information is available at the end of the article
}

decay is almost entirely preventable. A previous editorial has noted that 'Preventing oral disease is important and achievable' and that 'preventive approaches exist, but they need to be rigorously promoted and implemented' [2]. Clearly, prevention of disease is a more important tactic than treating established disease [3]. This cliché is often used in a general sense in the field of medicine, but rarely is it so prescient. Regardless of political theory and tactics in implementing public health policy, it is of concern that so many young children have already experienced dental decay. This does not augur well for these children in later life. It has been shown that children with caries in their deciduous teeth have a greater risk of
C Biomed Central

(c) 2011 McMahon et al; licensee BioMed Central Ltd. This is an Open Access article distributed under the terms of the Creative Commons Attribution License (http://creativecommons.org/licenses/by/2.0), which permits unrestricted use, distribution, and reproduction in any medium, provided the original work is properly cited. 
developing dental decay in their permanent teeth by the age of 12 [4].

Additional inspections of very young children at the start of their nursery education in NHS Greater Glasgow and Clyde have coincided with determined efforts by NHS Boards throughout Scotland to improve the dental health of all children. Two papers have recently been published which give a full account of the complex intervention known as the Childsmile programme [5,6]. The 'Demonstration' phase of the Childsmile programme covered the years 2006-2008. The current 'Interim' phase is intended to cover the years 2009-2011. The Childsmile programme consists of various interventions which are delivered at different stages of a child's life. The roll-out of the programme also proceeded in different sequences in different areas of Scotland.

Prior to the introduction of Childsmile a supervised nursery toothbrushing intervention with fluoride toothpaste was rolled out gradually from 1996 in NHS Greater Glasgow and Clyde. Over $90 \%$ of nursery establishments in the area were actively involved by 2006 , and this coverage has continued to the present day [7]. By mid 2006 the Childsmile Practice component of the national programme commenced in this area and involved needs assessment of newborns by Public Health Nurses and referral of identified children at increased risk of future decay into Childsmile $[5,6,8]$. The programme involved a novel skill-mix i.e. Extended Duties Dental Nurses and community-based Dental Health Support Workers. These new staff enabled better integration of complementary interventions based in the community with those taking place in the dental practice setting. The aim was to facilitate provision of appropriate needs-based oral health support to infants and their families from the earliest age, either through facilitation to visit dental practice or via individually tailored home-support by the support workers, working as part of the extended Public Health nursing team. At the Childsmile dental practices the dental nurses provided and implemented individualised Oral Health Promotion care-plans for each child and family.

The Oral Health Promotion programme rolled-out in an incremental manner in the NHS Board area commencing earliest in the most deprived districts. The number of infants' first visits to dental practices increased five-fold between 2006 and 2009; in mid-2008 dental practices were offered a fee for providing fluoride varnish treatment to children enrolled in the programme, from their second birthday onwards; by the middle of 2009, 28000 children in deprived areas had been given Childsmile risk-assessments for future dental decay by their Public Health Nurses; 14000 children were enrolled into Childsmile dental practices or clinics, and 10000 had begun making visits to respective dental practices [6]. The objective of this study was to examine dental inspection data from threeyear old children to assess the extent to which the 'basket' of activities comprising the Childsmile complex intervention had impacted on the dental health of three year old children in the NHS Greater Glasgow and Clyde area. The differential impacts across the spectrum of socioeconomic status were examined.

\section{Methods}

Dental inspections were carried out in nursery schools in the first (known as the ante-pre-school year) of the two years of nursery education that are normally completed by Scotland's children. The NDIP inspections are usually carried out on five-year old children in Primary One and eleven-year old children in Primary Seven. Full NDIP reports from 2003 onwards are freely available online [9]. Additional NDIP dental inspections of three-year old children in NHS Greater Glasgow and Clyde have been undertaken in the academic years of 2006/7, 2007/8, $2008 / 9$ and most recently in 2009/10. The NDIP data are generated as part of a Scottish Government oral health monitoring system and no further ethical approval is required for the analysis of this data. Legally, it is a statutory duty to inspect children at least twice. There is an option to opt-out of this programme but opt-in consent is not applicable.

A more detailed report of the methods and some results from 2006/7 and 2007/8 have previously been published [10]. In brief, the dental inspections were undertaken using standard British Association for the Study of Community Dentistry (BASCD) criteria, and all of the inspectors completed an annual training and calibration exercise immediately in advance of the dental inspections [11]. In the latest year of study we calibrated four examiners against an experienced 'gold standard' inspector, producing kappa scores for $\mathrm{d}_{3} \mathrm{mft}$ of 1.0, 1.0, 1.0, and 0.81 (based on one disagreement). The examiners had no knowledge of which components of the intervention had been experienced by individual children (or indeed in a school). After drying the teeth with cotton wool rolls and using standardised lighting conditions, the prevalence of 'obvious experience of dental decay which had extended into dentine' was recorded for each surface of each tooth. When using BASCD criteria, inspectors use a 'No. 4 plain' mirror and a CPITN probe (end diameter $0.5 \mathrm{~mm}$ ). Probe use is restricted to removal of debris, detection of sealants and restorative materials and to determine cavitated lesions (greater than $0.5 \mathrm{~mm}$ in diameter). The data were assessed by calculating $\mathrm{d}_{3} \mathrm{mft}$ (number of decayed missing or filled teeth), $\mathrm{d}_{3} \mathrm{t}$ (number of teeth with unrestored decay extending into the dentine), $\mathrm{mt}$ (number of missing teeth, due to decay), and $\mathrm{ft}$ (number of teeth previously decayed, now filled). A Scottish Index of Multiple Deprivation (SIMD) score was ascribed to each child's data, using their home 
postcode. The SIMD (2006) contains 37 indicators of socioeconomic deprivation and has been recommended for all prospective analyses of Scottish health statistics $[12,13]$. The SIMD scores have been divided into quintile groupings i.e. SIMD 1 represents the most deprived areas and SIMD 5 represents the most affluent areas. Data for children with an unknown SIMD score were removed from the analysis cohort.

Population weights were calculated by the inverse of the probability of being sampled. The probability of being sampled is the number of children examined, divided by the equivalent number of children in the population in each of the five SIMD quintiles. This type of weighting is used to protect against inspection samples which might under-represent or over-represent one or more of the SIMD categories in the population. The mean $\mathrm{d}_{3} \mathrm{mft}$ and the percentage of children with no obvious decay experience in each SIMD quintile were analysed by survey methods, and the attendant $95 \%$ confidence intervals were calculated.

In addition, univariate and adjusted logistic models were used to calculate odds-ratios and 95\% confidence intervals. In the adjusted models the effect of 'year of study' is adjusted by SIMD and age. In the univariate models, estimation of the c-index was used as a way of ranking the importance of the three variables in predicting dental decay, as all of the $\mathrm{p}$-values were too small to be useful in this regard [14]. The $\mathrm{c}$-index is the area under the curve of the lines of an ROC plot [15]. A variable with no predictive ability has a c-index of 0.5 and a variable with perfect predictive power has a c-index of 1.0. An interaction test between the effect of 'year of study' and SIMD was performed. Comparisons of the skewed $\mathrm{d}_{3} \mathrm{mft}$ data were carried out by Wilcoxon tests. Unadjusted mean $\mathrm{d}_{3} \mathrm{mft}$ statistics partitioned by SIMD categories for each year of study were also presented in a graph.

Bratthall has recommended using the 'Significant Caries Index' (SIC) to examine the distribution of $\mathrm{d}_{3} \mathrm{mft}$ in a population. The SIC score is the mean $\mathrm{d}_{3} \mathrm{mft}$ in the worst affected third of the population $[16,17]$. However, Morgan et al more recently recommend that a variety of cut-points should be used, with the choice depending on the research questions [18]. Thus, this study has used a variation of this method by calculating the mean $\mathrm{d}_{3} \mathrm{mft}$ for each twentieth of the population in ascending order of $\mathrm{d}_{3} \mathrm{mft}$. A graphical presentation for each SIMD in each year of study was used to illustrate distribution of $d_{3} m f t$ scores. The informative part of the graph is the tail of the distribution representing the children with the most dental decay. All analyses were carried out using SAS version 9.1 (SAS, Cary, NC), with survey analyses carried out using the SURVEYMEANS procedure.

\section{Results}

The number of children with usable data was 1711 for 2006/7, 2428 for 2007/8, 3300 for 2008/9 and 2583 for 2009/10, giving a total of 10022 children for all of the years combined. Due to their young age some children refused to participate on the day of their inspections $(9.6 \%$ on average). A total of 724 children were excluded due to the absence of a SIMD category. The breakdown by SIMD category of study subjects was 4688 with a score of 1 (the most deprived), 1669 with SIMD = 2, 1198 with SIMD = 3, 1004 with SIMD $=4$, and 1463 children having the most affluent category of SIMD $=5$. Thus the sample subjects were representative of the socioeconomic status of the background population [10]. Relative to the area's population of 3 year olds, the data analyses related to $14 \%$ of the population in $2006 / 7,19 \%$ in $2007 / 8,23 \%$ in 2008 / 9 , and $19 \%$ in $2009 / 10$.

The weighted results are presented in Table 1 for the percentage of children with obvious signs of dental decay experience, and in Table 2 for the mean $\mathrm{d}_{3} \mathrm{mft}$ (i.e. number of decayed, missing and filled teeth). The weighted percentage of children with decay experience in $2006 / 7$ and in $2007 / 8$ was $26 \%$ and $25 \%$, respectively. This reduced to $18 \%$ in $2007 / 8$ and $17 \%$ in $2009 / 10$. In univariate analyses, the ranking of the usefulness of each variable was: SIMD c-index $=0.60$, Age c-index $=0.56$, and Year c-index $=0.55$ (the children were all approximately three years old, which lowers the predictive ability of age in this study). The adjusted odds-ratio for decay experience in the most deprived areas versus the least deprived areas was 3.63 (95\% confidence interval (CI) $3.03,4.36, \mathrm{p}<0.001$ ), and the adjusted odds-ratio for a 12 months increase in age was 2.27 (95\% CI 1.92, 2.70, $\mathrm{p}<0.001$ ). When compared to the baseline year of 2006/ 7 the odds-ratios for prevalence of decay experience in subsequent years were 0.91 for $2007 / 8$ (95\% CI 0.79, 1.06, $\mathrm{p}=0.221), 0.63$ for $2008 / 9$ (95\% CI $0.55,0.72$, $\mathrm{p}<0.001)$, and 0.50 for $2009 / 10$ (95\% CI 0.43, 0.58, p < 0.001). After adjustment for deprivation and age, a large reduction in decay experience over time was observed, with the odds of decay experience (i.e. $\mathrm{d}_{3} \mathrm{mft}>0$ ) halving by the most recent year of study. Similar patterns in the results are evident from the analyses of mean $\mathrm{d}_{3} \mathrm{mft}$ (Table 2). The weighted mean $\mathrm{d}_{3} \mathrm{mft}$ was 1.1 in $2006 / 7,1.0$ in $2007 / 8$ ( $\mathrm{p}=0.869), 0.6$ in $2008 / 9(\mathrm{p}<0.001)$ and 0.4 in $2009 / 10$ $(\mathrm{p}<0.001)$.

Reductions in prevalence of dental decay experience were found in each of the five SIMD socioeconomic grades. For example, in the most deprived districts the percentage of children with obvious decay experience reduced from $33 \%(2006 / 7)$ to $24 \%(2009 / 10)$. The respective difference for children in the most affluent districts in the same time period was a reduction from 
Table $1 \%$ Obvious Dental Decay in Greater Glasgow and Clyde, Scotland

\begin{tabular}{|c|c|c|c|c|c|c|c|}
\hline \multirow[t]{2}{*}{ Year } & \multicolumn{5}{|c|}{ SIMD* } & \multirow[b]{2}{*}{ Total } & \multirow[b]{2}{*}{$\begin{array}{l}\text { Weighted } \\
95 \% \mathrm{Cl}\end{array}$} \\
\hline & 1 & 2 & 3 & 4 & 5 & & \\
\hline $2006 / 7$ & 216/655 (33\%) & $81 / 259$ (31\%) & $56 / 247$ (23\%) & 42/194 (22\%) & 46/356 (13\%) & $441 / 1711(26 \%)$ & 26\%: 24\%, 28\% \\
\hline $2007 / 8$ & $343 / 1068$ (32\%) & $114 / 414(28 \%)$ & 68/296 (23\%) & 35/237 (15\%) & $65 / 413(16 \%)$ & $625 / 2428(26 \%)$ & 25\%: 23\%, 27\% \\
\hline $2008 / 9$ & 415/1581 (26\%) & $117 / 541(22 \%)$ & 42/333 (13\%) & 44/323 (14\%) & $34 / 522$ (7\%) & $652 / 3300(20 \%)$ & 18\%: 17\%, 19\% \\
\hline $2009 / 10$ & 333/1384 (24\%) & $70 / 455$ (15\%) & $46 / 322(14 \%)$ & $25 / 250(10 \%)$ & 9/172 (5\%) & 483/2583 (19\%) & 17\%: 15\%, 18\% \\
\hline
\end{tabular}

Abbreviations: $\mathrm{Cl}$, confidence interval.

* SIMD $=$ Scottish index of multiple deprivation, $1=$ most deprived, $5=$ least deprived.

$13 \%$ to $5 \%$. There was a significant interaction between SIMD and year of study ( $\mathrm{p}=0.033)$, but this seems to have been generated by small differences in the oddsratios being emphasised by the very large sample size. The mean $\mathrm{d}_{3} \mathrm{mft}$ reduced from 1.5 to 0.5 for the most deprived areas, and reduced from 0.3 to 0.1 in the most affluent areas. The trends for each SIMD category can also be seen graphically in Figure 1 . The mean $\mathrm{d}_{3} \mathrm{mft}$ in each of the twentieths of the distribution of $\mathrm{d}_{3} \mathrm{mft}$ is given for each year in Figure 2. It can be seen that the curves for the twentieths with a mean of zero have moved towards the right, and the height of the tail has reduced progressively for the most recent two years. The actual mean $\mathrm{d}_{3} \mathrm{mft}$ in the 'worst twentieth', at the right of the plot, was 9.8 for 2006/7, 9.6 for $2007 / 8,7.7$ for $2008 / 9$, and 4.02 for 2009/10.

\section{Discussion}

This study has examined patterns of dental decay in four consecutive academic years for three-year old children in the NHS Greater Glasgow and Clyde area in the West of Scotland. The combined sample size of more than 10000 children, and the magnitude of the sampling fraction of the population, is large enough to make solid inferences and to create sub-groups using an area-based measure of socioeconomic status, such as the Scottish Index of Multiple Deprivation (SIMD). This is not a small research project that has tested whether a treatment may prove beneficial for patients with a particular diagnosis. By use of a 'directed-population' approach with differentially intensive interventions across the socioeconomic spectrum the Childsmile programme aims to promote measurable improvements in dental health at the level of the entire population [8,19-21]. In total, 10022 children (with deprivation data) were inspected, equivalent to an average of $19 \%$ of the entire eligible population of three year old children. The weighted proportion of children with obvious decay experience improved progressively over the two most recent years, so that ultimately decay experience reduced from $26 \%$ in $2006 / 7$ to $17 \%$ in 2009/10. In a logistic regression model which adjusted directly by SIMD and age, the relative reduction appeared to be even greater, namely $50 \%$ which corresponds to the odds-ratio (OR) of 0.5 (note that the unadjusted $\mathrm{OR}=0.66$, adjusted by age $\mathrm{OR}=0.61$, adjusted by SIMD OR $=0.55$, adjusted by both age and SIMD OR $=0.50$ ). In other words, the relative reduction in the children studied is estimated at $50 \%$, and in the population at large (weighted by SIMD but unadjusted by age) it is estimated at $35 \%$. Presumably, if the entire population had been inspected the true population reduction would lie between these two estimates.

The relative improvements in dental health were seen across the socioeconomic spectrum, which is precisely what the recent independent reports for the World Health Organisation and the UK government advocate if health inequalities are to decrease in the future $[22,23]$. It can be seen in Figure 2 that reductions were clearly evident in even the worst affected twentieth of the distribution, as measured by $d_{3} m f t$. This is arguably because Childsmile adopts a life-course approach commencing at the earliest age with differentially intensive interventions customised to meet individuals' assessed oral health needs [23]. The Childsmile interventions tailored for individuals are over and above the universal programme

Table 2 Mean $d_{3}$ mft (number of decayed, missing or filled teeth) in Greater Glasgow and Clyde, Scotland

\begin{tabular}{|c|c|c|c|c|c|c|c|}
\hline \multirow[t]{2}{*}{ Year } & \multicolumn{5}{|c|}{ mean (standard deviation) for each SIMD* } & \multirow[b]{2}{*}{ Total } & \multirow[b]{2}{*}{$\begin{array}{c}\text { Weighted } \\
95 \% \mathrm{Cl}\end{array}$} \\
\hline & 1 & 2 & 3 & 4 & 5 & & \\
\hline $2006 / 7$ & $1.5(3.0)$ & $1.3(2.7)$ & $0.9(2.2)$ & $0.7(1.8)$ & $0.3(1.2)$ & $1.1(2.5)$ & 1.1: $1.0,1.2$ \\
\hline $2007 / 8$ & $1.4(2.9)$ & $0.9(2.0)$ & $0.9(2.2)$ & $0.5(1.6)$ & $0.5(1.5)$ & $1.0(2.4)$ & 1.0: $0.9,1.1$ \\
\hline $2008 / 9$ & $1.0(2.3)$ & $0.7(1.9)$ & $0.4(1.4)$ & $0.4(1.3)$ & $0.2(0.9)$ & $0.7(1.9)$ & $0.6: 0.6,0.7$ \\
\hline $2009 / 10$ & $0.5(1.2)$ & $0.4(1.1)$ & $0.3(0.9)$ & $0.2(0.8)$ & $0.1(0.4)$ & $0.4(1.1)$ & $0.4: 0.3,0.4$ \\
\hline
\end{tabular}

Abbreviations: $\mathrm{Cl}$, confidence interval.

* SIMD $=$ Scottish index of multiple deprivation, $1=$ most deprived, $5=$ least deprived 


\section{Mean dmft by SIMD}

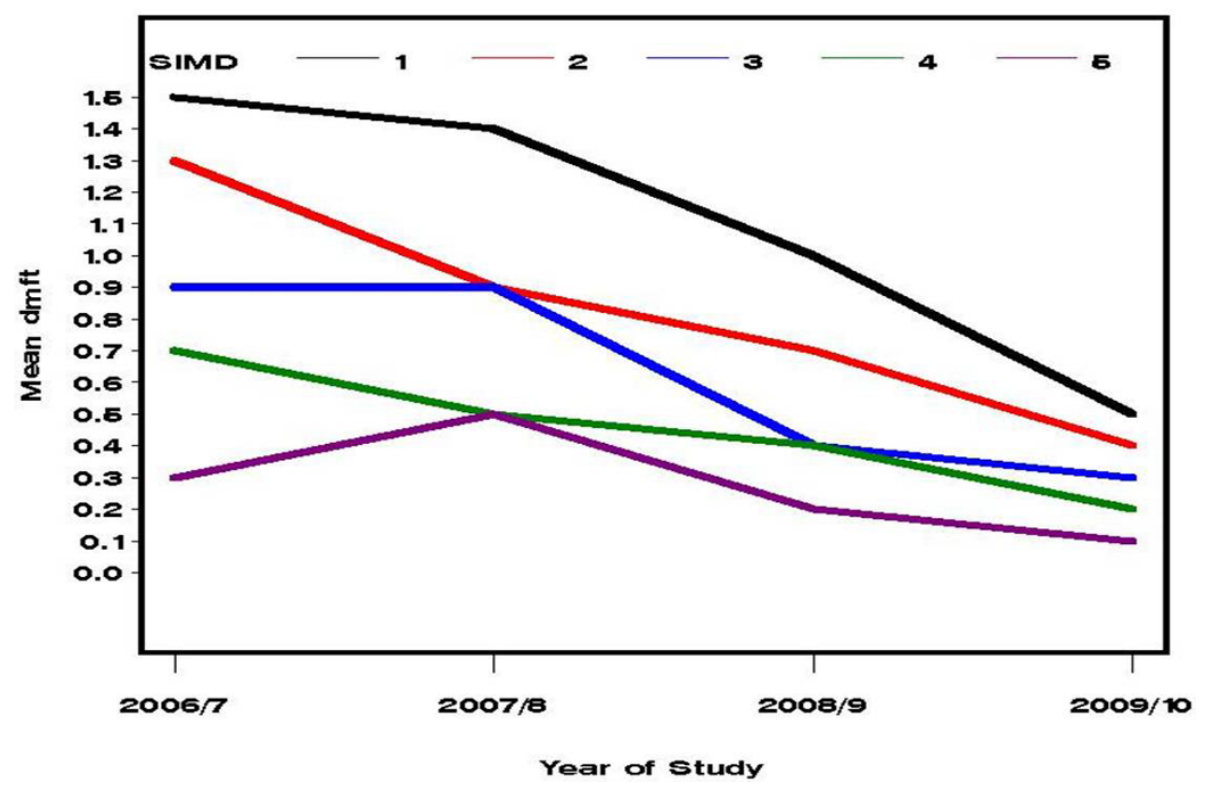

Figure 1 Analysis of mean $d_{3} m f t$ by Scottish Index of Multiple Deprivation (SIMD, $1=$ most deprived, $5=$ least deprived) in Greater Glasgow and Clyde, Scotland.

elements e.g. daily supervised 1000 ppm F toothbrushing in all nurseries. The absolute improvement in obvious decay experience was $9 \%$ for the poorest areas and $8 \%$ for the most affluent areas (Table 1). In considering mean $\mathrm{d}_{3} \mathrm{mft}$ scores, it appears that the poorest children have benefited the most with an absolute improvement of 1.0 compared to only 0.2 for children in the most affluent areas (Table 1, Figure 1).

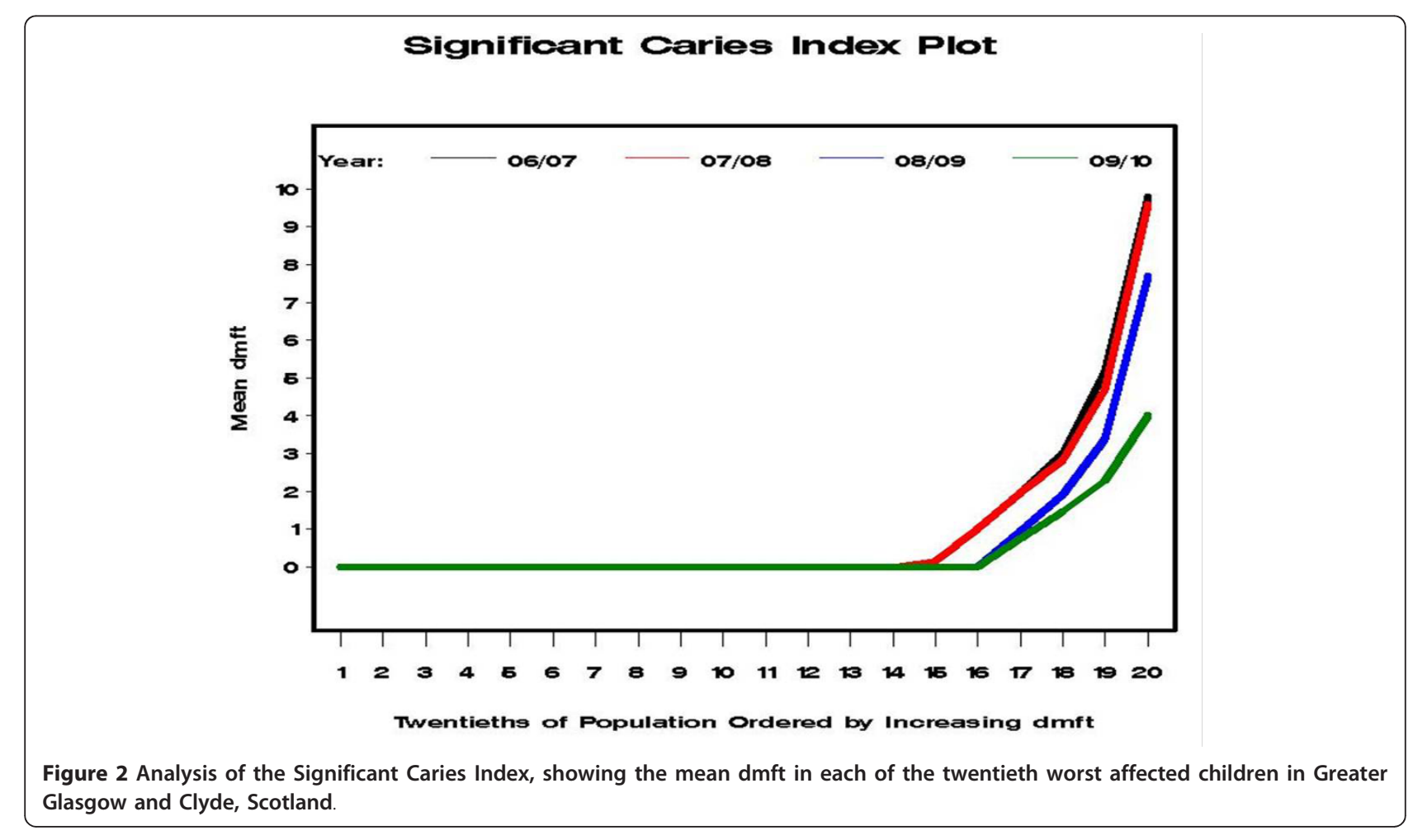


It is interesting that the weighted reduction in mean $\mathrm{d}_{3} \mathrm{mft}$ in the overall population is more noticeable between 2008/9 and 2009/10 (0.7 and 0.4, respectively) than that for the proportion with obvious decay experience $(18 \%$ to $17 \%)$. Generally, we expect a strong relationship in dental health between mean $\mathrm{d}_{3} \mathrm{mft}$ and the percentage of subjects with decay [24]. However, a short lag is plausible in a backdrop of decreasing dental decay as this could follow Sheiham's Rule that 'as caries prevalence falls, the less susceptible sites (proximal and smooth surfaces) reduce by the greatest proportion, whilst the most susceptible sites (occlusal) reduce by the smallest proportion' [25]. In other words, some teeth and tooth surfaces are more resistant to improvement in a population than others, which militates against children becoming completely free of caries. However, in the directly adjusted logistic model the odds-ratio for 2008/9 versus $2006 / 7$ was 0.63 , and that for $2009 / 10$ was 0.50 , so there is some encouraging evidence of a progressive drop in obvious decay experience. Furthermore, there are sound theoretical reasons for the above magnitudes of improvement to have happened in NHS Greater Glasgow and Clyde following such interventions [26]. It is anticipated that these improvements will continue once Childsmile is embedded into the NHS Scotland remuneration system.

These results contrast sharply with those of a recent paper 'Giving Children a Healthy Start' by the Audit Commission [27]. It is of concern that the Audit Commission reports that in spite of a $£ 7.2$ billion investment in England's Sure Start (1998/99-2010/11), five-year-olds' mean $\mathrm{d}_{3} \mathrm{mft}$ values are deteriorating both in England as a whole and in their specially targeted 'Spearhead areas' $\left(+0.29 \mathrm{~d}_{3} \mathrm{mft}\right.$, i.e. $\left.+19.9 \%\right)$. These trends contrast markedly with those observed for NHS Greater Glasgow and Clyde over the same period and are suggestive that the trends described here have not been part of a wider secular trend. Moreover, it has been considered that there is a pending wider public health crisis in many countries due to contemporary increases in children's dental caries prevalence [28].

\section{Conclusions}

This study demonstrates that it is possible to impact upon both the prevalence and morbidity of dental decay across the socioeconomic spectrum in a population. Surely this type of 'anticipatory care' model is an improvement, when compared to the traditional model of 'reactive dental care' and is worthy of consideration for implementation elsewhere [3]. In the past, West of Scotland children from deprived backgrounds first experience of dental services was frequently for 'crisis care' [29]. Furthermore, a recent independent review noted that the NHS in 2009 is still dealing with, and paying for, the consequences of disease that developed more than 50 years ago' and making a transition in tactics will be a challenge [30]. At present, NHS Greater Glasgow and Clyde is the only NHS Board in Scotland to conduct epidemiological studies of its resident three-year-olds. This endeavour has helped produce our conclusion that the dental health of three year old children in the NHS Greater Glasgow and Clyde area has improved in recent years.

\section{Acknowledgements and Funding}

The results are based on annual NDIP inspections conducted within nurseries in NHS Greater Glasgow and Clyde. We acknowledge the support and co-operation of all concerned. The data collection was funded by NHS Greater Glasgow and Clyde.

\section{Author details}

${ }^{1}$ Community Oral Health, Level 8, University of Glasgow Dental School, 378 Sauchiehall St, Glasgow, G2 3JZ, Scotland, UK. ${ }^{2} \mathrm{NHS}$ Greater Glasgow and Clyde, Oral Health Directorate, 120 Cornwall St South, Glasgow, G41 4AH, Scotland, UK.

\section{Authors' contributions}

All authors contributed to the design of the study and interpretation of the data. ADM wrote the first draft and conducted the statistical analyses. YB trained and calibrated the dental inspectors. All authors contributed to the writing of the manuscript, and have read and approved the final manuscript.

\section{Competing interests}

The authors declare that they have no competing interests.

Received: 4 March 2011 Accepted: 28 October 2011

Published: 28 October 2011

\section{References}

1. Petersen PE: The World Oral Health Report 2003: continuous improvement of oral health in the 21st century-the approach of the WHO Global Oral Health Programme. Community Dentistry and Oral Epidemiology 2003, 31(Suppl S1):3-23.

2. Editorial: Oral health: prevention is key. The Lancet 2009, 373; 9657:1.

3. The Scottish Government (2007): Better Health, Better Care: Action Plan. The Scottish Government, Edinburgh; 2007 [http://www.scotland.gov.uk] Resource/Doc/194854/0052337.pdf], (Accessed 16th June 2011).

4. Peres MA, Barros AJ, Peres KG, Araújo $C L$, Menezes AM: Life course dental caries determinants and predictors in children aged 12 years: a population-based birth cohort. Community Dentistry and Oral Epidemiology 2009, 37:123-133.

5. Macpherson LM, Ball GE, Brewster L, Duane B, Hodges CL, Wright W, Gnich W, Rodgers J, McCall DR, Turner S, Conway DI: Childsmile: the national child oral health improvement programme in Scotland. Part 1: establishment and development. British Dental Journal 2010, 209:73-78.

6. Turner S, Brewster L, Kidd J, Gnich W, Ball GE, Milburn K, Pitts NB, Goold S, Conway DI, Macpherson LM: Childsmile: the national child oral health improvement programme in Scotland. Part 2: monitoring and delivery. British Dental Journal 2010, 209:79-83.

7. NHS Greater Glasgow (2005): Evaluation of NHS Greater Glasgow Oral Health Action Teams. A report from the Monitoring and Evaluation Subgroup of the OHAT Steering Group, November 2005. Glasgow, NHS Greater Glasgow; [http://library.nhsgg.org.uk/mediaAssets/library/ nhsggc_report_oral_health_action_team_evaluation_2005-11.pdf], (Accessed 16th June 2011).

8. Shaw D, Macpherson L, Conway D: Tackling socially determined dental inequalities: ethical aspects of Childsmile, the national child oral health demonstration programme in Scotland. Bioethics 2009, 23; 2:131-139.

9. National Dental Inspection Programme Reports. [http://www. scottishdental.org/index.aspx?o=2153], (Accessed 16th June 2011). 
10. McMahon AD, Blair Y, McCall DR, Macpherson LM: The dental health of three year old children in Greater Glasgow, Scotland. British Dental Journal 2010, 209; 4:E5.

11. Pitts NB, Evans DG, Pine CM: British Association for the Study of Community Dentistry (BASCD) diagnostic criteria for caries prevalence surveys - 1996/97. Community Dental Health 1997, 14(Suppl 1):6-9.

12. Scottish Executive: Using the Scottish Index of Multiple Deprivation 2006. One Scotland, Scottish Executive. Scottish Executive National Statistics Publication; 2006 [http://www.scotland.gov.uk/Resource/Doc/151598/ 0040732.pdf], (Accessed 16th June 2011).

13. Measuring Deprivation Subgroup. Deprivation and urban rural measurements in ISD. Summary Report, 2004. ISD, Edinburgh; 2010 [http://www.isdscotland.org/isd/files/Measuring_deprivation_in_ISD_v3.pdf], (Accessed 16th June 2011).

14. Harrell FE, Lee KL, Mark DB: Multivariable prognostic models: issues in developing models, evaluating assumptions and adequacy, and measuring and reducing errors. Statistics in Medicine 1996, 15:361-387.

15. Altman DG, Bland JM: Diagnostic tests 3: receiver operating characteristic plots. BMJ 1994, 309:188.

16. Bratthall D: Introducing the Significant Caries Index together with a proposal for a new global oral health goal for 12-year-olds. International Dental Journal 2000, 50; 6:378-384.

17. Antunes JLF, Narvai PC, Nugent ZJ: Measuring inequalities in the distribution of dental caries. Community Dentistry and Oral Epidemiology 2004, 32; 1:41-48.

18. Morgan MZ, Chestnutt IG, Treasure ET: Summary measures of caries prevalence to describe high-risk communities. Community Dental Health 2005, 22:246-252.

19. Fejerskov O: Strategies in the design of preventive programs. Advances in Dental Research 2005, 9; 2:82-88.

20. Watt RG: Strategies and approaches in oral disease prevention and health promotion. Bulletin of the World Health Organization 2005, 83: 9:711-718.

21. Batchelor PA, Sheiham A: The distribution of burden of dental caries in schoolchildren: a critique of the high-risk caries prevention strategy for populations. BMC Oral Health 2006, 6:3.

22. Marmot M: Closing the gap in a generation: Health equity through action on the social determinants of health. Geneva, World Health Organization; 2008 [http://www.who.int/social_determinants/ thecommission/finalreport/en/index.html], (Accessed 16th June 2011).

23. Marmot M: Fair Society, Healthy Lives. The Marmot Review. Strategic Review of Health Inequalities in England post-2010. London, The Marmot Review; 2010 [http://www.marmotreview.org/], (Accessed 16th June 2011).

24. Sheiham A, Sabbah W: Using universal patterns of caries for planning and evaluating dental care. Caries Research 2010, 44:141-150.

25. Sheiham A: Impact of dental treatment on the incidence of dental caries in children and adults. Community Dentistry and Oral Epidemiology 1997. 25:104-112.

26. Scottish Intercollegiate Guidelines Network, (2000). Scottish Intercollegiate Guidelines Network 47: Prevention of dental caries in children at high caries risk. NHS Quality Improvement Scotland. Edinburgh, Scottish Intercollegiate Guidelines Network; [http://www.sign.ac.uk/guidelines/fulltext/ 47/section3.html], (Accessed 16th Feb 2011).

27. Audit Commission: Giving Children a Healthy Start. A review of health improvements in children from birth to five years. London, Audit Commission Publishing Team ; 2010 [http://www.audit-commission.gov.uk/ health/nationalstudies/publichealth/Pages/ GivingChildrenaHealthyStart_copy.aspx], (Accessed 16th June 2011).

28. Bagramian RA, Garcia-Godoy F, Volpe AR: The global increase in dental caries. A pending public health crisis. American Journal of Dentistry 2009, 22; 1:3-8.

29. Macpherson LM, Pine CM, Tochel C, Burnside G, Hosey MT, Adair P: Factors influencing referral of children for dental extractions under general and local anaesthesia. Community Dental Health 2005, 22; 4:282-288.

30. Steele J: NHS Dental Services in England: An independent review led by Professor Jimmy Steele. Executive Summary. NHS; 2009 [http://www.dh. gov.uk/en/Publicationsandstatistics/Publications/

PublicationsPolicyAndGuidance/DH_101137], (Accessed 16th June 2011).

\section{Pre-publication history}

The pre-publication history for this paper can be accessed here: http://www.biomedcentral.com/1472-6831/11/29/prepub

doi:10.1186/1472-6831-11-29

Cite this article as: McMahon et al:: Reductions in dental decay in 3-year old children in Greater Glasgow and Clyde: repeated population inspection studies over four years. BMC Oral Health 2011 11:29.

\section{Submit your next manuscript to BioMed Central and take full advantage of:}

- Convenient online submission

- Thorough peer review

- No space constraints or color figure charges

- Immediate publication on acceptance

- Inclusion in PubMed, CAS, Scopus and Google Scholar

- Research which is freely available for redistribution

Submit your manuscript at www.biomedcentral.com/submit
C Biomed Central 